\title{
Copper (II) Complexes of New Carboxyamide Ligands: Synthesis, Spectroscopic and Antibacterial Study
}

\author{
P. Ramesh ${ }^{1,2}$, M.Revathi ${ }^{1,}$ Ammar Adil.H ${ }^{1}$, N.A.AL-Satar Mohammeda ${ }^{1}$, S. Siddappa $^{1}$, \\ P. Muralidhar Reddy ${ }^{1^{*}}$, Chand Pasha ${ }^{3^{*}}$ \\ ${ }^{1}$ Department of Chemistry, Nizam College, Osmania University, Hyderabad, India \\ ${ }^{2}$ Department of Chemistry, S.R\&B.G.N.R. Government College, Khammam, India \\ ${ }^{3}$ Department of Microbiology, Nizam College, Osmania University, Hyderabad, India \\ pmdreddy@gmail.com, cpasha21@gmail.com
}

\begin{abstract}
Copper (II) complexes with three carboxyamide ligands viz.2 (phenylcarbamoyl) benzoic acid (PCBCH),(Z)-4-(2-nitrophenylamino)-4-oxobut-2-enoic acid (NPAOEH) and (2Z, 2'Z)-4, 4'-(1,2-phenylenebis (azanediyl)) bis (4-oxobut-2-enoic acid) (PEAOBH) have been synthesized and characterized by UV-Visible, Infrared and ${ }^{1} H$-NMR spectral data. Analytical data support 1: 2 stoichiometry for metal: ligand. The molar conductivity data indicate that the complexes are non-electrolytic in nature. The electronic spectra suggests distorted octahedral geometry for $\mathrm{Cu}$ (II) complexes. The antibacterial activity of all the ligands and complexes against gram-positive and gram-negative bacteria was compared with the activity of existing commercial antibacterial compound like Streptomycin. All metal complexes found to be more active than respective ligands.
\end{abstract}

Keywords: Antibacterial activity, Carboxyamide Ligand, Copper complexes

\section{INTRODUCTION}

The amide group, an important structural feature of proteins, can be described as resonating between two structures (Fig.1), one with the double bond between the carbon atom and the oxygen atom, and the other with the double bond between the carbon atom and the nitrogen atom ${ }^{1}$.

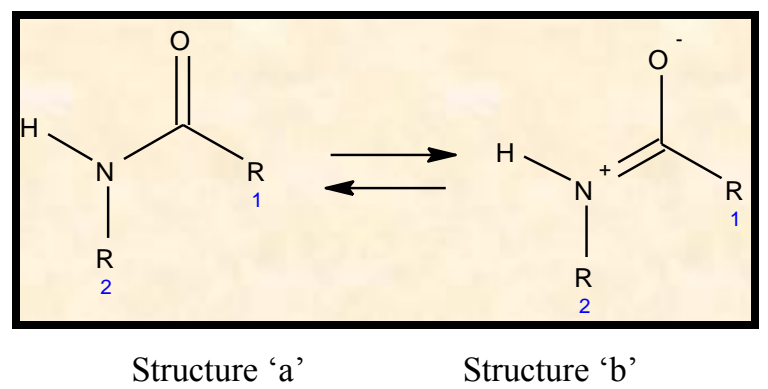

Fig1. Resonance structures of amide group

General arguments about the stability of alternative structures indicate that the structure with the double bond between carbon and oxygen should contribute somewhat more to the normal state of the amide group than the other structure; experience with other substances and acquaintance with the results of quantum mechanical calculations suggest the ratio 60\%: $40 \%$ for the respective contributions of these structures. A $40 \%$ contribution of the structure with the double bond between the carbon atom and the nitrogen atom would confer upon this bond the property of planarity of the group of six atoms. The estimate of $40 \%$ double-bond character for the $\mathrm{C}-\mathrm{N}$ bond is supported by the experimental value of the bond length, $1.32 \AA$, interpreted with the aid of the empirical relation between double-bond character and inter-atomic distance ${ }^{2}$. Knowledge of the structure of amides and also of the amino acids, provided by the theory of resonance and verified by extensive careful experimental studies made by R. B. Corey and his coworkers, has been of much value in the determination of the structure of the amide complexes. It is known that the amide groups to retain their planarity, the atoms are expected not to deviate from the planar configuration by more than perhaps $0.05 \AA$ A.Amide group being the repeating unit of the biologically important polypeptide 
macromolecules, it has attracted the attention of the chemists to synthesize the coordination compounds of transition metal ions with the ligands containing amide and to study the structure, antifungal, antibacterial and physiological activity of the ligands and their metal complexes ${ }^{3-6}$.

There are numerous examples of amide group containing compounds therapeutically important like Bleomycins. Rehder ${ }^{7}$ and McNeill ${ }^{8}$ have published comprehensive reviews in this area. In addition to the biological activity of the amide group containing ligands show diversified coordinating behavior in their metal complexes. According to the studies of Kroneck and co-workers ${ }^{9}$ the diverse coordinating behavior of amide group in the complexes not only depends on the nature of the metal ion but also on the C-terminal and the N-terminal substituents of the amide (-CO-NH-) group. The involvement of carboxyl group in the chelation depends upon the second donor atom at the correct spacing for the formation of a stable chelate ring ${ }^{10,11}$.Additionally, Our research group reported the synthesis, catalytic and biologically active coordination compounds of $\mathrm{Ru}(\mathrm{II}), \mathrm{Ru}(\mathrm{III}), \mathrm{Pd}(\mathrm{II}), \mathrm{Cu}(\mathrm{II})$, $\mathrm{Fe}(\mathrm{II}), \mathrm{Fe}(\mathrm{III}), \mathrm{Co}(\mathrm{III}), \mathrm{Ni}(\mathrm{II}), \mathrm{Pt}(\mathrm{II})$ and $\mathrm{Rh}(\mathrm{III})$ with various amides/Schiff base ligands ${ }^{12-32}$. Likewise, a convenient solid state synthesis of some carboxy amides under solvent free conditions was also reported by us ${ }^{12}$. Results from these studies have also shown that chelation tend to make nonbiologically active compounds biologically active ${ }^{33,34}$ and already biologically active compounds to be more active $21,23,26,30-32$. In continuation of our work, we herewith present the synthesis and characterization of $\mathrm{Cu}$ (II) complexes with above three amide ligands and also been screened for their antibacterial activities.

\section{EXPERIMENTAL}

\subsection{Materials}

All the organic solvents, amines, acid anhydrides, and metal salts used in this study were of analar grade. The solvents were distilled by standard procedures before use. The three ligands used in this work were prepared and characterized by IR, UV-Visible and ${ }^{1} \mathrm{H}-\mathrm{NMR}$ spectral data. The water used in the study was essentially double distilled water. The solvents were distilled and stored over molecular sieves. The purity of the compounds was checked by TLC using Merck 60F254 silica gel plates

\subsection{Physical Measurements}

The melting points of all the ligands were determined on a Buchi- 510 melting point apparatus. The melting points of the complexes could not be determined as the complexes were found to decompose before melting.UV-Visible spectra were recorded with Shimadzu UV-2140A, a UV-Visible double beam spectrophotometer with matched quartz cells of path length $1 \mathrm{~cm}$ at Nizam College (Autonomous) Osmania University, Hyderabad. The IR spectra were recorded in $\mathrm{KBr}$ pellets on Perkin Elmer-283 spectrophotometer at Osmania University, Hyderabad. The scanning rate was 6 min in the range of 4000-200 $\mathrm{cm}^{-1}$. The ${ }^{1} \mathrm{H}-\mathrm{NMR}$ spectra were obtained from Chem Draw software. Hot air oven (Instrument and equipment Pvt. Ltd., Mumbai), incubator (Instrument and equipment Pvt. Ltd., Mumbai), laminar air flow unit (Claslaminar technologies Pvt. Ltd. Secunderabad), autoclave (Medica instrument Mfg.Co. Mumbai) were used in the antimicrobial investigations. The antimicrobial activity of the compounds was determined by the cup plate method and the minimum inhibitory concentration by liquid dilution method.

\subsection{Synthesis of Ligands}

\subsubsection{Preparation of 2-(phenylcarbamoyl) Benzoic Acid (PCBCH)}

Finely powdered phthalic anhydride(3.14gms,33.756m.moles) is dissolved in ethyl acetate then add Aniline $(3.08 \mathrm{ml})$ with constant stirring by using magnetic stirrer, a white color precipitate is produced i.e. 2-(phenylcarbamoyl)benzoic acid (PCBCH). The colorless precipitate formed on cooling the hot solution was suction filtered, washed with diethyl ether, recrystallized twice from methanol and dried in vacuum. The white powder formed (PCBCH) gave only one spot with TLC in 1:2 mixture of methyl acetate and 1-butanol tested in perpendicular directions (yield 90\%).

\subsubsection{Preparation of (Z)-4-(2-nitrophenylamino)-4-Oxobut-2-Enoic Acid (NPAOEH)}

In a solvent free reaction take finely powdered Maleic anhydride $(4.78 \mathrm{gms}, 50.981 \mathrm{~m}$.moles) it is dissolved in ethanol then add $o$-Nitro Aniline $(4.6 \mathrm{ml})$ with constant stirring by using magnetic stirrer, blue color precipitate is produced i.e. . (Z)-4-(2-nitrophenylamino)-4-oxobut-2-enoic acid, The blue 
color powder formed gave only one spot with TLC in 1:2 mixture of ethyl acetate $\&$ hexane tested in perpendicular directions (yield 92\%).

\subsubsection{Preparation of (2Z, $\left.2^{\prime} Z\right)-4,4^{\prime}-(1,2-$ phenylenebis(azanediyl))bis(4-Oxobut-2-Enoic Acid)(PEA $\mathrm{OBH})$}

In a solvent free reaction take finely powdered maleic anhydride $(5 \mathrm{gms})$ it is dissolved in ethyl acetate then add Orthophenalene diamine (5.12gms) with constant stirring by using magnetic stirrer. Brown color precipitate is produced i.e. (2Z,2'Z)-4,4'-(1,2-phenylenebis(azanediyl))bis(4-oxobut-2-enoic acid). The precipitate formed the above gave only one spot with TLC in 1:2 mixture of ethyl acetate \& hexane tested in perpendicular directions (yield 85\%).

\subsection{Synthesis of $\mathrm{Cu}$ (II) Complexes of PCBCH, NPAOEH and PEAOBH}

A solution of metal salt $\mathrm{CuSO}_{4} 7 \mathrm{H}_{2} \mathrm{O}(0.002 \mathrm{~mol})$ in 1:1 mixture methanol and water $(20 \mathrm{~mL})$ was added to a solution of the ligand $(0.002 \mathrm{~mol})$ in methanol $(25 \mathrm{~mL})$ with constant stirring. The reaction mixture was refluxed on a water bath for 1-2 $\mathrm{h}$ or until a solid separated out. The solids were suction filtered, purified by repeated washing with 1:1 diethyl ether, methanol mixture and dried in vacuum over anhydrous calcium chloride (yield 85-90\%).

\subsection{Antimicrobial Activity}

Organisms like Escherichia coli, Klebsiella pneumonia, Basillus subtilis, Staphylococcus aureus, were used for the In vitro antibacterial studies of all synthesized ligands and their $\mathrm{Cu}$ (II) complexes. Antibiotics such as Streptomycin, was used as the standards for the antibacterial activity studies. Antibacterial testing was done by cup plate method ${ }^{35}$. A standard microorganism media viz. nutrient agar medium and nutrient broth medium (supplied by Hi-media, Mumbai) used for the bacterial studies. A $1000 \mu \mathrm{g} / \mathrm{ml}$ testing sample solution (amide ligands and their $\mathrm{Cu}(\mathrm{II})$ metal complexes) was prepared by dissolving $10 \mathrm{mg}$ of it in $10 \mathrm{ml}$ of a suitable solvent (initially water, methanol and DMSO) ${ }^{36}$. Solutions with different concentrations such as $120,110,100,90,80,70,60,50,45,40$, $35,30,25,20,15,10,5,2,1 \mu \mathrm{g} / \mathrm{ml}$ were prepared from the sample solution by further dilution. Sterile Petri dishes were taken to which $27 \mathrm{ml}$ of molten agar is added and allowed to solidify and set for $1 \mathrm{hr}$. Then $50 \mathrm{ml}$ of the 24 hours culture of a test organism was taken on to the agar plate and spread evenly with the sterile cotton swab. $6 \mathrm{~mm}$ wide bores were made on the agar using a borer. The solutions of the ligands and $\mathrm{Cu}$ (II) complexes were added into each of the bores in appropriately using a sterile tip with micropipette and labeled as Petri dishes. Similar plates were also prepared for Standard antibiotics. These dishes were then incubated aerobically at the $37{ }^{\circ} \mathrm{C}$ for 24 hours with bacterial cultures ${ }^{37}$. The zones of inhibition of growth were found compared with standard antibiotics. The activities of compounds were interpreted as active, inactive. The minimum inhibitory concentration required was also found when a series of dilutions were tested.

\section{RESUlts AND Discussion}

\subsection{Characterization of Ligands}

All the ligands used in the study are prepared by the general method of the reaction of an anhydride with an amine.

\subsubsection{Analytical Data}

The physical data including color, melting points and percentage yield presented in Table.1

Table1. Physical and analytical data of amide ligands

\begin{tabular}{|c|c|c|c|c|}
\hline S.No & Ligand & Color & Melting Point & \% Of Yield \\
\hline 1 & PCBCH & White & 162 & $90 \%$ \\
\hline 2 & NPAOEH & Blue & 110 & $92 \%$ \\
\hline 3 & PEAOBH & Brown & 153 & $85 \%$ \\
\hline
\end{tabular}

\subsubsection{IR Spectra}

All the ligands show a broad $v(\mathrm{O}-\mathrm{H})$ stretching band centering near $3100 \mathrm{~cm}^{-1}$ and another broad band corresponding to $\delta(\mathrm{O}-\mathrm{H})$ bending vibration between $840-990 \mathrm{~cm}^{-1}$ assigned to $\mathrm{COOH}$ group. The $v(\mathrm{O}-$ $\mathrm{H})$ stretching band is superimposed on the $\left.v(\mathrm{~N}-\mathrm{H})\left(3330-3270 \mathrm{~cm}^{-1}\right)\right)$ stretching band, while the broad wings of the O-H stretch can be seen on either side of the N-H band. The spectra of the ligands also 
contain characteristic bands corresponding to $v(\mathrm{C}=\mathrm{O})$ of $\mathrm{COOH}, \mathrm{v}(\mathrm{C}=\mathrm{O})$ (amide), $\mathrm{v}(\mathrm{C}-\mathrm{N})$ and $\mathrm{v}(\mathrm{C}-\mathrm{O})$ of $\mathrm{COOH}$ respectively ${ }^{1,2}$ at $1680-1710,1640-1680,1380-1440$ and $1280-1350 \mathrm{~cm}^{-1}$ indicating the formation of amide.

\subsection{3. ${ }^{1}$ HMR Spectra}

The ${ }^{1}$ HMR spectral data of the ligands are obtaining from Chem. office. It can be seen from the below that all the ligands show signals corresponding to the carboxyl protons as singlets indicating chemical shifts in the range 11.0-11.5 $\delta$ and that of amide proton as broad singlets between 9.00-9.8 $\delta$. These signals confirm the formation of an amide and not an imide.

\subsubsection{Electronic Spectra}

The electronic spectra of PCBCH, NPAOEH and PEAOBH are taken in methanol/DCM (Figures $2 \& 3)$. In the UV-visible spectra of all these compounds the first peak is due to the $\pi \rightarrow \pi^{*}$ transitions of the heterocyclic ring and the second one is due to the $\mathrm{n} \rightarrow \pi^{*}$ transition of the $-\mathrm{C}=\mathrm{O}-$ group in the carboxy amide ligands.

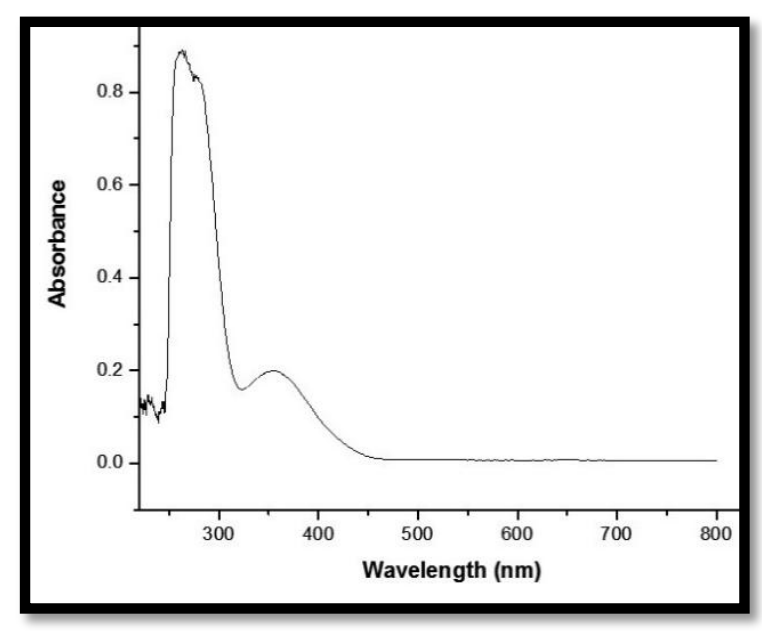

Figure2. $U V$-Vis spectrum of $P C B C H$

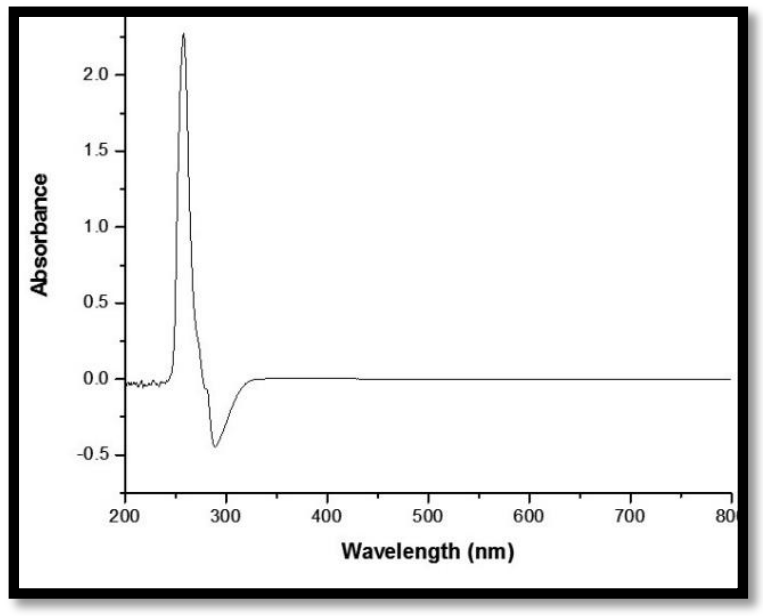

Figure3. $U V$-Vis spectrum of PEAOBH

\subsection{Characterization of $\mathrm{Cu}$ (II) Complexes}

Copper is one of the most extensively studied transition metal ion in terms of complex formation. The dipositive state of copper is the most important oxidation state and the usual coordination numbers adopted by copper (II) are four, five and six. Fairly a large number of six, four coordinated complexes and relatively less number of five coordinated complexes are reported. Distorted octahedral geometry for the six coordination, square planar and tetrahedral dispositions for four coordination and square pyramidal or trigonal bipyramidal arrangements for five coordination have been assigned. A number of copper (II) complexes exhibit five coordination, with trigonal bipyramidal geometry, the simplest being $\mathrm{CuCl}_{5}^{-3}$ ion.

Copper (II) ion with its $\mathrm{d}^{9}$-electronic configuration in octahedral or tetrahedral environment is highly susceptible to John-Teller distortion. Particularly six coordinated complexes are severely distorted from octahedral symmetry to tetragonal arrangements, with majority of them having axially elongated structures, as revealed by x-ray studies. In tetrahedral environment also, John-Teller distortion is operative, in spite of the fact that large spin orbit coupling constant might produce sufficient splitting of the $\mathrm{T}_{2}$ ground state. There are more examples of distorted tetrahedral dispositions, when compared to regular tetrahedral arrangement in $\mathrm{Cu}$ (II) complexes.

Octahedral complexes without any distortions are expected to have one d-d absorption band corresponding to ${ }^{2} \mathrm{E}_{\mathrm{g}} \rightarrow^{2} \mathrm{~T}_{2 \mathrm{~g}}$ transition. For distorted octahedral complexes, several weak bands are observed around $16,000 \mathrm{~cm}^{-1}$ and often a broad tail in the near infrared region due to John-Teller effect. In the axially elongated tetragonal coordination, ${ }^{2} \mathrm{~B}_{\mathrm{lg}}$ represents the ground state and three absorption bands corresponding to the transitions; ${ }^{2} \mathrm{~B}_{1 \mathrm{~g}} \rightarrow{ }^{2} \mathrm{~A}_{1 \mathrm{~g}},{ }^{2} \mathrm{~B}_{1 \mathrm{~g}} \rightarrow{ }^{2} \mathrm{~B}_{2 \mathrm{~g}}$, and ${ }^{2} \mathrm{~B}_{1 \mathrm{~g}} \rightarrow{ }^{2} \mathrm{E}_{\mathrm{g}}$ are observed.

Tetrahedral complexes do not have any d-d-transition in the region of $10,000-20,000 \mathrm{~cm}^{-1}$ in visible spectrum, only low energy charge transfer bands may be observed in this region. The ground term in corresponding square planar geometry is ${ }^{2} \mathrm{~B}_{1 \mathrm{~g}}$ and three $\mathrm{d}-\mathrm{d}$ transition corresponding transitions 
${ }^{2} \mathrm{~B}_{1 \mathrm{~g}} \rightarrow^{2} \mathrm{~B}_{2 \mathrm{~g}}{ }^{2} \mathrm{~B}_{1 \mathrm{~g}} \rightarrow^{2} \mathrm{~A}_{1 \mathrm{~g}}$, and ${ }^{2} \mathrm{~B}_{1 \mathrm{~g}} \rightarrow^{2} \mathrm{E}_{\mathrm{g}}$ are observed.

The observed magnetic moments of many mononuclear copper (II) complexes are in the range of 1.75-2.18 B.M. Lower values are observed only in the case of poly nuclear complexes.

\subsubsection{Conductance Measurements}

The molar conductance values of $\mathrm{Cu}$ (II) complexes in DMF at $10^{-3} \mathrm{M}$ concentration are low (8.8$18.5 \mathrm{mho} \mathrm{mole}^{-1} \mathrm{~cm}^{2}$ ) suggesting that they are non-electrolytes. ${ }^{38}$

\subsubsection{IR Spectra}

The characteristic IR bands data of all the $\mathrm{Cu}$ (II) complexes is presented in (Table 2). The IR spectra of PCBCH, NPAOEH and PEAOBH complex of copper (II) showed broad band in the region of $2750-3400 \mathrm{~cm}^{-1}$. However the broad bands present in the infrared spectra of the three complexes in this region are broader compared to the respective ligands. This together with the medium sharp nonligand bands at $750-850 \mathrm{~cm}^{-1}$ present in the infrared spectra of the four complexes indicate the presence of coordinated water in the complexes.

In all the copper(II) complexes the bands due to amide $v(\mathrm{C}=\mathrm{O})$ mode around $1660 \mathrm{~cm}^{-1}$ for the free ligands are shifted to lower frequency by $25-40 \mathrm{~cm}^{-1}$ while the amide $v(\mathrm{C}-\mathrm{N})$ shifted to higher frequency in all the complexes. This result is explained by the lengthening of the $\mathrm{C}=\mathrm{O}$ bond and shortening of the C-N bond which cause decrease and increase of the frequencies respectively which confirms the coordination of amide group to the metal ion via carbonyl oxygen in all the complexes. A non-ligand medium band in the region of $310-350 \mathrm{~cm}^{-1}$ assignable to $v(\mathrm{M}-\mathrm{O})$ are observed in all the complexes further supporting the coordination of the oxygen of the amide $\mathrm{C}=\mathrm{O}$ of the ligands to the metal ion. ${ }^{39}$

The absorption bands around $1700 \mathrm{~cm}^{-1}$ and $1330 \mathrm{~cm}^{-1}$ in the free ligands attributed to $v(\mathrm{C}=\mathrm{O})$ and $v(\mathrm{C}-\mathrm{OH})$ of the carboxyl group are replaced by two bands in the region of $1550-1560 \mathrm{~cm}^{-1}$ and $1330-$ $1350 \mathrm{~cm}^{-1}$ corresponding to $v(\mathrm{COO})_{\text {asy }}$ and $v(\mathrm{COO})_{\text {sym }}$ in all the $\mathrm{Cu}(\mathrm{II})$ complexes. This indicates deprotonation of the carboxyl groups of the ligands and coordination of the groups to the metal ion through the oxygen of the carboxyl group. A non-ligand medium strong band in the region of 420-465 $\mathrm{cm}^{-1}$ assignable to $v(\mathrm{M}-\mathrm{O})$ are observed in all the complexes further supporting the coordination of the carboxyl oxygen of the ligands to the metal ion. One of the bands due to Amide ring $v(\mathrm{C}=\mathrm{N})$ mode at about $1660 \mathrm{~cm}^{-1}$ for the free PCBCH, NPAOEH and PEAOBH ligands is shifted to lower frequency by 25 and $50 \mathrm{~cm}^{-1}$ in their Copper(II) complexes indicating the coordination of one of the amide nitrogen atoms to the metal ion in the complexes. The additional non-ligand band observed in the copper (II) complexes at about $550 \mathrm{~cm}^{-1}$ assignable to $v(\mathrm{M}-\mathrm{N})$ further supports the involvement of amide nitrogen of the PCBCH, NPAOEH and PEAOBH ligands in the complexation.

Table2. IR (in $\left.\mathrm{cm}^{-1}\right)$ Spectral Data of Cu(II) Complexes

\begin{tabular}{|c|c|c|c|c|c|c|c|}
\hline Complex & v(N-H) & v(CO)amide & v(COO)asym & v(COO)sym & v(C-N) & v(M-N) & v(M-O) \\
\hline$\left[\mathrm{Cu}(\mathrm{PCBCH}) \mathrm{CH}_{2} \mathrm{O}\right.$ & $3270-3310$ & 1625 & 1550 & 1327 & 1580 & 520 & 330 \\
\hline$\left[\mathrm{Cu}(\mathrm{NPAOEH}) 2 \mathrm{H}_{2} \mathrm{O}\right]$ & $3200-3400$ & 1600 & 1583 & 1344 & 1583 & 513 & 393 \\
\hline$\left[\mathrm{Cu}(\mathrm{PEAOBH}) 2 \mathrm{H}_{2} \mathrm{O}\right]$ & $3000-3500$ & 1629 & 1408 & 1300 & 1400 & 510 & 310 \\
\hline
\end{tabular}

\subsubsection{Electronic Spectra}

The electronic spectra of the copper(II) complexes of PCBCH, NPAOEH and PEAOBH recorded in methanol $\left(10^{-3} \mathrm{M}\right)$ showed d-d bands in the regions $20,000-13,000 \mathrm{~cm}^{-1}(500-770 \mathrm{~nm})$ which can be assigned to ${ }^{2} \mathrm{~T}_{2} \mathrm{~g} \leftarrow{ }^{2} \mathrm{Eg}$ transition of an octahedral geometry. Though in cases where the ${ }^{2} \mathrm{Eg}$ and ${ }^{2} \mathrm{~T}_{2} \mathrm{~g}$ states of the octahedral $\mathrm{Cu}(\mathrm{II})$ ion $\left(\mathrm{d}^{9}\right)$ split under the influence of the tetragonal distortion the three transitions ${ }^{2} \mathrm{E}_{\mathrm{g}} \leftarrow{ }^{2} \mathrm{~B}_{1 \mathrm{~g}},{ }^{2} \mathrm{~B}_{2 \mathrm{~g}} \leftarrow{ }^{2} \mathrm{~B}_{1 \mathrm{~g}}$, and ${ }^{2} \mathrm{~A}_{1 \mathrm{~g}} \leftarrow{ }^{2} \mathrm{~B}_{1 \mathrm{~g}}$ are expected, their very close energies could have made them appear in the form of one broad band envelope. Our results are in good agreement with those reported for a distorted octahedral geometry around $\mathrm{Cu}(\mathrm{II})$ ion. The spectra of copper (II) complexes exhibit broad d-d absorption bands in the region 500-770 $\mathrm{nm}$ indicative of a distorted octahedral system with weak apical coordination of solvent/anion molecules. The magnetic and electronic data point to distorted octahedral environments for $\mathrm{Cu}$ (II) ions in complexes.

\section{Antimicrobial Activity}

Based on the results, the amide ligands showed no activity or having low to moderate activity. In contrast, the $\mathrm{Cu}$ (II) metal complexes were found to be very active against the two types each of Gram 
(+ve) (B. subtilis and S. aureus) and Gram $(-\mathrm{ve})($ E. coli and $K$. pneumonia $)$ bacteria. The rise in the antimicrobial activity of $\mathrm{Cu}$ (II) metal chelates possibly because of the effect of the metal ion on the normal cell process. According to the Tweedy's chelation theory ${ }^{40}$, chelation noticeably decreases the polarity of the metal ion due to partial sharing of its positive charge with donor groups and probable $\pi$-electron delocalization over the whole chelate ring. This chelation possibly will enhance the lipophilic nature of the central metal atom, which then favors its penetration through the lipid layers of cell membrane ${ }^{40,41}$. Further, these active amide $\mathrm{Cu}$ (II) metal complexes were examined to assess their minimum inhibitory concentration (MIC) (Table 3). According to the results, the $\mathrm{Cu}$ (II) complexes were found to be active at lower concentrations than the existing antibiotics like Streptomycin.

Table3. MIC values of the antimicrobial activity of amide ligands, their $\mathrm{Cu}$ (II) complexes and existing antibiotics

\begin{tabular}{|c|c|c|c|c|}
\hline Compound & Escherichia Coli & $\begin{array}{c}\text { Klebsiella } \\
\text { Pneumonia }\end{array}$ & $\begin{array}{c}\text { Basillus } \\
\text { Subtilis }\end{array}$ & $\begin{array}{c}\text { Staphylococcus } \\
\text { Aureus }\end{array}$ \\
\hline PCBCH & - & 85 & 90 & - \\
\hline $\mathrm{NPAOEH}$ & 100 & - & - & 95 \\
\hline PEAOBH & - & 95 & 90 & 80 \\
\hline$\left[\mathrm{Cu}(\mathrm{PCBCH})\left(\mathrm{H}_{2} \mathrm{O}\right)_{2}\right]$ & 35 & 40 & 35 & 30 \\
\hline$\left[\mathrm{Cu}(\mathrm{NPAOEH})\left(\mathrm{H}_{2} \mathrm{O}\right)_{2}\right]$ & 30 & 35 & 25 & 30 \\
\hline$\left[\mathrm{Co}(\mathrm{PEAOBH})\left(\mathrm{H}_{2} \mathrm{O}\right)_{2}\right]$ & 20 & 20 & 25 & 20 \\
\hline Streptomycin $^{\mathrm{a}}$ & 35 & 40 & 40 & 45 \\
\hline
\end{tabular}

${ }^{a}$ Standard for antibacterial studies

\section{ConClusions}

In the present investigations, $\mathrm{Cu}$ (II) complexes with three carboxyamide ligands were synthesized and distorted octahedral structures were proposed tentatively on the basis of analytical and spectral data. All the $\mathrm{Cu}$ (II) complexes along withexisting antibacterial drugswere screened for antibacterial activityagainst Gram (+ve) (B. subtilis, S. aureus) and Gram (-ve) (E. coli, K.pneumonia) bacteria. All these complexes were found to be moreactive when compared to streptomycin.

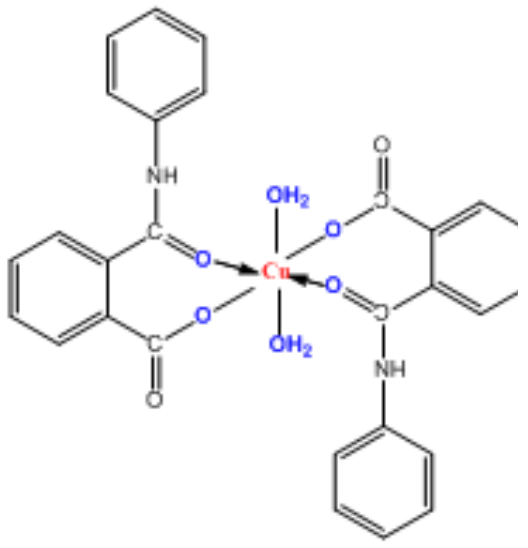

$\left[\mathrm{Cu}(\mathrm{PCBCH})_{2}\left(\mathrm{H}_{2} \mathrm{O}\right)_{2}\right]$

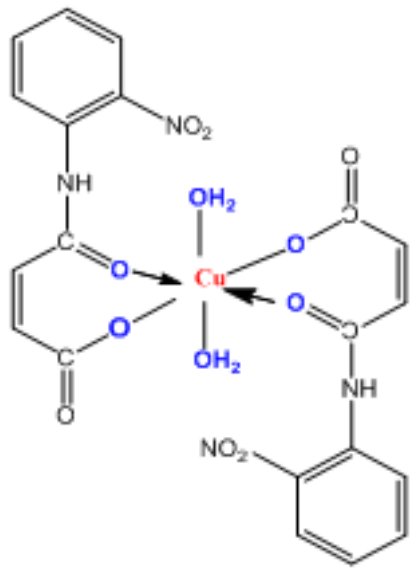

$\left[\mathrm{Cu}(\mathrm{NPAOEH})_{2}\left(\mathrm{H}_{2} \mathrm{O}\right)_{2}\right]$<smiles>Nc1ccccc1NC(=O)OP1(O)(O)OC(=O)C=CC(=O)OC(Nc2ccccc2N)=CC(=O)O1</smiles>

$\left[\mathrm{Cu}(\mathrm{PEAOBH})_{2}\left(\mathrm{H}_{2} \mathrm{O}\right)_{2}\right]$

\section{REFERENCES}

[1] Pauling, L. The Electronic Structure of the Normal Nitrous Oxide Molecule. Proceedings of the National Academy of Sciences of the United States of America18, 498-499 (1932).

[2] Pauling, L., Brockway, L.O. \& Beach, J.Y. The Dependence of Interatomic Distance on Single Bond-Double Bond Resonance1. Journal of the American Chemical Society57, 2705-2709 (1935).

[3] Atwell, G.J., Cain, B.F., Baguley, B.C., Finlay, G.J. \& Denny, W.A. Potential antitumor agents. Part 43. Synthesis and biological activity of dibasic 9-aminoacridine-4-carboxamides, a new class of antitumor agent. Journal of Medicinal Chemistry27, 1481-1485 (1984). 
[4] Mohan, M., Kumar, A., Kumar, M. \& Jha, N.K. Synthesis, characterization and antitumor activity of manganese(II), cobalt(II), nickel(II), copper(II), zinc(II) and platinum(II) complexes of 3- and 5-substituted salicylaldehyde benzoylhydrazones. Inorganica Chimica Acta136, 65-74 (1987).

[5] Parwana, H.K., Singh, G. \& Talwar, P. Antifungal activity of metal complexes of thiosemicarbazones. Inorganica Chimica Acta108, 87-89 (1985).

[6] Thimmaiah, K.N., Lloyd, W.D. \& Chandrappa, G.T. Structural features of biologically active coordination compounds of vanillinsemicarbazone. Transition Metal Chemistry10, 94-96 (1985).

[7] Rehder, D. The coordination chemistry of vanadium as related to its biological functions. Coordination Chemistry Reviews 182, 297-322 (1999).

[8] McNeill, J.H., Yuen, V.G., Hoveyda, H.R. \& Orvig, C. Bis(maltolato)oxovanadium(IV) is a potent insulin mimic. Journal of Medicinal Chemistry35, 1489-1491 (1992).

[9] Kroneck, P.M.H., Vortisch, V. \& Hemmerich, P. Model Studies on the Coordination of Copper in Biological Systems. European Journal of Biochemistry109, 603-612 (1980).

[10] Sigel, H. Deprotonation of Glycine Amide in a Ternary Copper(II)-Complex. Angewandte Chemie International Edition in English7, 137-138 (1968).

[11] Sigel, H., Prijs, B. \& Martin, R.B. Stability of binary and ternary $\beta$-alanine containing dipeptide copper(II) complexes [1]. Inorganica Chimica Acta56, 45-49 (1981).

[12] Ravinder, V., Rani, P.U. \& Balaswamy, G. Solid state synthesis of some carboxy amides under solvent-free conditions. Indian Journal of Heterocyclic Chemistry14, $73-74$ (2004).

[13] Ashok, M., Prasad, A. \& Ravinder, V. Synthesis, spectral studies and catalytic activity of ruthenium(II) complexes with organic amide ligands. Journal of the Brazilian Chemical Society18, 1492-1499 (2007).

[14] Ashok, M., Prasad, A., Reddy, P.M. \& Ravinder, V. Synthesis, spectral studies, and catalytic and antibacterial activity of $\mathrm{Ru}(\mathrm{II})$ complexes with coordinated amides. Journal of Applied Spectroscopy75, 864-871 (2008).

[15] Ashok, M., Prasad, A.V.S.S., Reddy, P.M. \& Ravinder, V. Ru(III)-catalyzed oxidation of pyridoxine and albuterol in pharmaceuticals. Spectrochimica Acta Part A: Molecular and Biomolecular Spectroscopy72, 204-208 (2009).

[16] Ashok, M., Ravinder, V. \& Prasad, A. Synthesis, spectral characterization and catalytic applications of $\mathrm{Ru}(\mathrm{II})$ complexes with amide ligands. Transition Metal Chemistry32, 23-30 (2007).

[17] Gade, D., Gubba, B., Vadde, R. \& Puri, L. Mössbauer and other spectral studies of iron(II) complexes with amide-containing ligands. Transition Metal Chemistry12, 539-543 (1987).

[18] Gade, D. \& Puri, L. Synthesis and spectral studies of platinum complexes with amide-group containing ligands. Transition Metal Chemistry14, 203-205 (1989).

[19] Ravindar, V., Lingaiah, P. \& Reddy, K.V. Studies on ruthenium(II) complexes with ligands containing the amide group. Inorganica Chimica Acta87, 35-40 (1984).

[20] Ravindar, V., Swamy, S.J., Srihari, S. \& Lingaiah, P. Synthesis and spectral studies of copper(II) complexes with amide group ligands. Polyhedron4, 1511-1518 (1985).

[21] Reddy, M.B. et al. New cobalt(II) tetraaza macrocyclic complexes: Synthesis, spectral and antimicrobial studies. Journal of the Indian Chemical Society84, 971-977 (2007).

[22] Reddy, P.M., Ashok, M., Narasaiah, V. \& Ravinder, V. Synthesis, structure, reactivity and electrochemical studies of oxovanadium(IV) chelates with some carboxyamide derivatives. Journal of the Indian Chemical Society83, 973-979 (2006).

[23] Reddy, P.M., Prasad, A.V.S.S. \& Ravinder, V. Synthesis, spectral characterization, catalytic and antibacterial activity of macrocyclic CuII compounds. Transition Metal Chemistry32, 507-513 (2007).

[24] Reddy, P.M., Prasad, A.V.S.S., Reddy, C.K. \& Ravinder, V. Synthesis of new macrocyclic rhodium(III) compounds and their utility as catalysts for the oxidation of ascorbic acid. Transition Metal Chemistry33, 251-258 (2008). 
[25] Reddy, P.M., Prasad, A.V.S.S., Rohini, R. \& Ravinder, V. Catalytic reduction of pralidoxime in pharmaceuticals by macrocyclic $\mathrm{Ni}(\mathrm{II})$ compounds derived from orthophthalaldehyde. Spectrochimica Acta Part A: Molecular and Biomolecular Spectroscopy70, 704-712 (2008).

[26] Reddy, P.M., Prasad, A.V.S.S., Shanker, K. \& Ravinder, V. Synthesis, spectral studies and antibacterial activity of novel macrocyclic Co(II) compounds. Spectrochimica Acta - Part A: Molecular and Biomolecular Spectroscopy68, 1000-1006 (2007).

[27] Reddy, P.M., Reddy, C.K., Rani, K.S., Reddy, M.B. \& Rivinder, V. Hydrido Ru-II organometallics; synthesis, spectral and catalytic hydrogenation studies. Journal of the Indian Chemical Society84, 733-738 (2007).

[28] Reddy, P.M., Shanker, K., Rani, P.U., Rao, B.K. \& Ravinder, V. Spectral and catalytic hydrogenation studies of Ru-II organometallics containing substituted tertiary phosphines. Journal of the Indian Chemical Society84, 411-417 (2007).

[29] Reddy, P.M., Shanker, K., Rohini, R., Sarangapani, M. \& Ravinder, V. Substituted tertiary phosphine $\mathrm{Ru}(\mathrm{II})$ organometallics: Catalytic utility on the hydrolysis of etofibrate in pharmaceuticals. Spectrochimica Acta Part A: Molecular and Biomolecular Spectroscopy70, 1231-1237 (2008).

[30] Shanker, K., Reddy, P.M., Rohini, R., Ho, Y.P. \& Ravinder, V. Encapsulation of Pd(II) by N4 and N2O2 macrocyclic ligands: their use in catalysis and biology. Journal of Coordination Chemistry62, 3040-3049 (2009).

[31] Shanker, K., Rohini, R., Ravinder, V., Reddy, P.M. \& Ho, Y.-P. Ru(II) complexes of N4 and N2O2 macrocyclic Schiff base ligands: Their antibacterial and antifungal studies. Spectrochimica Acta Part A: Molecular and Biomolecular Spectroscopy73, 205-211 (2009).

[32] Shanker, K. et al. Synthesis of tetraaza macrocyclic Pd-II complexes; antibacterial and catalytic studies. Journal of the Indian Chemical Society86, 153-161 (2009).

[33] Mastrolorenzo, A., Scozzafava, A. \& Supuran, C.T. Antifungal activity of Ag(I) and Zn(II) complexes of aminobenzolamide (5-sulfanilylamido-1,3,4-thiadiazole-2-sulfonamide) derivatives. Journal of Enzyme Inhibition15, 517-531 (2000).

[34] Mastrolorenzo, A., Scozzafava, A. \& Supuran, C.T. Antifungal activity of silver and zinc complexes of sulfadrug derivatives incorporating arylsulfonylureido moieties. European Journal of Pharmaceutical Sciences11, 99-107 (2000).

[35] Alam, S. Synthesis, antibacterial and antifungal activity of some derivatives of 2-phenylchromen-4-one. Journal of Chemical Sciences116, 325-331 (2004).

[36] Socransky, S.S., Dzink, J.L. \& Smith, C.M. Chemically defined medium for oral microorganisms. Journal of Clinical Microbiology22, 303-305 (1985).

[37] Cushnie, T.P.T. \& Lamb, A.J. Antimicrobial activity of flavonoids. International Journal of Antimicrobial Agents 26, 343-356 (2005).

[38] Geeta, B. et al. Binuclear cobalt(II), nickel(II), copper(II) and palladium(II) complexes of a new Schiff-base as ligand: Synthesis, structural characterization, and antibacterial activity. Spectrochim. Acta A 77, 911-915 (2010).

[39] Penland, R.B., Mizushima, S., Curran, C. \& Quagliano, J.V. Infrared Absorption Spectra of Inorganic Coördination Complexes. X. Studies of Some Metal-Urea Complexes1a,b. Journal of the American Chemical Society79, 1575-1578 (1957).

[40] Tweedy, B. Plant extracts with metal ions as potential antimicrobial agents. Phytopathology55, 910-914 (1964).

[41] Agh-Atabay, N.M., Dulger, B. \& Gucin, F. Structural characterization and antimicrobial activity of 1,3-bis(2-benzimidazyl)-2-thiapropane ligand and its $\mathrm{Pd}(\mathrm{II})$ and $\mathrm{Zn}(\mathrm{II})$ halide complexes. European Journal of Medicinal Chemistry40, 1096-1102 (2005). 